\title{
Systematic review and meta-analysis of smat
bowel dose-volume and acute toxicity in conventionally-fractionated rectal cancer radiotherapy
}

Daniel L.P. Holyoake FRCR, Mike Partridge PhD, Maria A. Hawkins FRCR*

\author{
*Corresponding author. Correspondence address: \\ CRUK/MRC Oxford Institute for Radiation Oncology \\ Department of Oncology \\ University of Oxford \\ Old Road Campus Research Building \\ Roosevelt Drive \\ Oxford \\ OX3 7DQ
}

Telephone: +44 (0)1865 225842

Fax: +44 (0) 1865857127

Email address: maria.hawkins@oncology.ox.ac.uk

Running head: Meta-analysis of small-bowel dose-volume-toxicity

Manuscript pages: 9 including title page, abstract page and references. Figures: 3. Tables: 3

Keywords: Rectal cancer; small bowel; toxicity; normal tissue; systematic review; meta-analysis.

Highlights

- Acute GI toxicity is highly prevalent and dose-limiting in the treatment of rectal cancer

- The dose-volume relationship for the small bowel is inadequately understood

- We have conducted meta-analysis of published dose-volume-histogram datasets

- We found a significant increase in toxicity with increased irradiated volume

- We also showed increased risk with increased dose for a given irradiated volume

Acknowledgements: MAH is funded by UK Medical Research Council grant MC_UU_00001/2 


\section{Abstract}

\section{Introduction}

The limited radiation tolerance of the small-bowel causes toxicity for patients receiving conventionallyfractionated radiotherapy for rectal cancer. Safe radiotherapy dose-escalation will require a better understanding of such toxicity. We conducted a systematic review and meta-analysis using published datasets of small bowel dose-volume and outcomes to analyse the relationship with acute toxicity.

\section{Materials and Methods}

SCOPUS, EMBASE \& MEDLINE were searched to identify twelve publications reporting small-bowel dosevolumes and toxicity data or analysis. Where suitable data were available (mean absolute volume with parametric error measures), fixed-effects inverse-variance meta-analysis was used to compare cohorts of patients according to Grade $\geq 3$ toxicity. For other data, non-parametric examinations of irradiated smallbowel dose-volume and incidence of toxicity were conducted, and a univariate logistic regression model was fitted.

\section{Results}

On fixed-effects meta-analysis of three studies (203 patients), each of the dose-volume measures $V_{5 G y}-V_{40 G y}$ were significantly greater $(p<0.00001)$ for patients with Grade $\geq 3$ toxicity than for those without. Absolute difference was largest for the lowest dose-volume parameter; however relative difference increases with increasing dose. On logistic regression multiple small-bowel DVH parameters were predictive of toxicity risk $\left(V_{5 G y}, V_{10 G y}, V_{30 G y}-V_{45 G y}\right)$, with $V_{10 G y}$ the strongest $(p=0.004)$.

\section{Conclusions}

Analysis of published clinical cohort dose-volume data provides evidence for a significant dose-volume-toxicity response effect for a wide range of clinically-relevant doses in the treatment of rectal cancer. Both low dose and high dose are shown to predict toxicity risk, which has important implications for radiotherapy planning and consideration of dose escalation for these patients. 


\section{Introduction}

Among patients receiving preoperative chemoradiotherapy for rectal cancer, CTC Grade $\geq 2$ acute gastrointestinal toxicity is seen in $20 \%$ of patients, and Grade $\geq 3$ in $10 \%$ [1]. This toxicity causes treatment to be suspended, altered, or even terminated prematurely, in up to $5 \%$ of patients [2], and failure to deliver treatment per protocol may have implications for achieving tumour control.

Much of this toxicity can be attributed to inadvertent irradiation of the small bowel, for which the dose-volume toxicity relationship was reviewed nearly a decade ago in the QUANTEC programme [3]. It is believed radiotherapy dose escalation [4] and novel radiation drug combinations may improve disease response in rectal cancer, however a better understanding of the radiation tolerance of the small-bowel will be required for these to be implemented safely. The aim of this work was to refine dose-volume toxicity relationship parameters for small-bowel radiation toxicity incorporating cohort-based datasets with detailed dose-volumehistogram data for rectal cancer patients treated with chemoradiation.

\section{Method and materials}

\section{Literature search}

The SCOPUS, EMBASE, and MEDLINE electronic databases were searched systematically using appropriate subject headings and key words, such as small bowel, ileum, jejunum, toxicity and radiation/radiotherapy, for papers published in English since 2002. The PRISMA recommendations were followed where possible [5]. Publications were then identified that analysed and/or provided small bowel dose-volume histogram (DVH) values, for patients treated with conventionally fractionated radiotherapy.

\section{Data Analysis}

Published DVH data were collated directly where possible. In some cases [6, 7], plot digitisation was used to analyse published figures in order to derive numerical data values when these had not been included in the publication (Table $1 \& 2$ in supplementary material). In some cases, cubic spline fitting was used to recreate a DVH from reported data points, and subsequently impute missing values (Figure 2 and Table 6 ,

supplementary material). Different toxicity grading scales (CTC v2, CTCAE v3, and RTOG) were examined and aligned to enable comparisons across publications (Table 3 in supplementary material).

Mean difference, inverse-variance, fixed-effect meta-analysis was carried out using the Cochrane Review Manager [8]. The volume of small bowel receiving a given dose (5 Gy to $40 \mathrm{~Gy}$, in 5-Gy bins) was compared between cohorts of patients with Grade $\geq 3$ toxicity and those without. The included studies were assessed for bias and heterogeneity using the Cochrane tools and Handbook [9]. Funnel plots were generated [10] and heterogeneity was formally evaluated using Chi-squared and $I^{2}$.

Other methods were used to analyse the data from studies not suitable for inclusion in formal meta-analysis:

Values for observed toxicity incidence within a published clinical cohort ('toxicity incidence' column, Table 1) were compiled in a matrix according to the small-bowel dose-volume parameters reported for that clinical cohort, in a manner based on the method proposed by Jackson et al. [11]. Where data from more than one 
publication were entered into a cell, the resultant overall toxicity incidence was derived. The proportional toxicity risk values were then used to render a heat-map of toxicity risk according to dose and volume. The absolute values are presented in the matrix, so that the denominator is known for each data point, and thus the relative confidence in the values derived for each cell can be ascertained.

Proportional toxicity incidence was analysed against cohort values for dose-volume parameters $\mathrm{V}_{5 \mathrm{~Gy}}-\mathrm{V}_{50 \mathrm{G} y}$ using univariate logistic regression modelling [12], [13]. For the parameters where a significant relationship was demonstrated, threshold values were derived associated with a toxicity risk of $20 \%$.

\section{Results}

\section{Literature review}

Ten publications were identified which reported analysis of the dose-volume toxicity relationship for the small bowel (Table 1), including one study which failed to show a dose-volume-toxicity effect [14]. Four of these studies had been included in the QUANTEC review, [6, 15-17], each of which reporting that all of the small bowel DVH parameters they tested $\left(\mathrm{V}_{5 \mathrm{~Gy}}-\mathrm{V}_{40 \mathrm{~Gy}}\right)$ were significantly associated with risk of acute toxicity.

\section{Data analysis}

Nine studies reported small bowel DVH data that could be extracted for analysis, from a total of 659 patients (Table 1 ). The median rate of Grade $\geq 3$ toxicity was $21 \%$ (range $4 \%$ to $35 \%$ ). The DVH values themselves are included in the supplementary material (Tables $5 \& 6$ ).

\section{Formal meta-analysis}

Three of the nine publications that reported data did so in a consistent manner suitable for incorporation in formal meta-analysis, namely mean volumes of small bowel irradiated according to acute small bowel or lower GI toxicity (Grade 0-2 versus Grade $\geq 3$ ) [18-20]. For each study the data was collected from observation of patients treated with rectal cancer treated with radical conformal radiotherapy using $1.8 \mathrm{~Gy}$ per fraction and concomitant 5-FU. For all dose-volume parameters tested $\left(\mathrm{V}_{5 \mathrm{~Gy}}-\mathrm{V}_{40 \mathrm{~Gy}}\right)$, the small bowel volume irradiated was significantly greater for patients who suffered Grade $\geq 3$ toxicity, as shown in Figure 1 (individual forest plots are included in the supplementary material, Figure 5). The absolute difference in irradiated volume for Grades $0-2$ versus Grade $\geq 3$ is largest for the lowest dose and decreases with increasing dose. However, the relative difference in volume increases with increasing dose, as shown in Table 2. On all three rounds of leave-one out sensitivity analysis, the 'treatment effect' (difference in small-bowel volume) lay within the 95\% confidence intervals for the primary analysis, suggesting the overall result is not dependent on the inclusion of any one particular study.

\section{Assessment of heterogeneity and bias}

The analysis of bias revealed certain sources of potential high risk, including high risk of selective reporting (where not all relevant data generated in the work are reported), and confounding factors. These included patient sex (for Banerjee et al. all the patients who suffered grade $\geq 3$ toxicity were female), pre- or postoperative radiotherapy (for Robertson et al. preoperatively treated patients had a lower incidence of Grade 3 acute diarrhoea than postoperatively treated patients), and extent and method of small-bowel delineation (absolute small-bowel volumes will be dependent on the extent of the CT scan). The funnel plots show standard error in the treatment effect against the absolute treatment effect, and where the data points do not all fall within the expected triangular distribution, heterogeneity of effect size is indicated (supplementary 
material, Figure 6). The presence of heterogeneity has also been confirmed by statistically significant results for all tested dose-volume parameters on Chi-squared testing, demonstrating that the observed variability in effect size is unlikely to have arisen through chance alone ( $p \leq 0.05$, Table 9 , supplementary table). Furthermore all $\mathrm{I}^{2}$ values (a quantitative indicator of the degree of heterogeneity) were between $67 \%$ and $85 \%$, lying within the range of $50 \%$ to $90 \%$ specified by the Cochrane Handbook that 'may represent substantial heterogeneity' [9].

\section{Informal cross-trial analysis}

The other papers identified in the literature search reported DVH data using a variety of measurements or criteria which meant their data could not be included in the formal meta-analysis. However, when informal analysis was undertaken using the data from these studies, there it is again shown that a significantly larger volume of small bowel has been irradiated for patients with higher grade of toxicity (Table 3 . Differences in cumulative (a) absolute and (b) relative volume of small bowel irradiated at each dose level between patients with or without toxicity as defined in each study. Relative change for data from Tho et al. could not be included as the irradiated volume for the patients without toxicity was zero. (c) As shown in the formal meta-analysis, the largest absolute difference was seen for the lowest dose parameter $\left(V_{5 G y}, 196 \mathrm{~cm}^{3}\right)$, and the difference decreased sequentially as the dose increased. The largest relative difference was seen for the $\mathrm{V}_{40 \mathrm{~Gy}}(175 \%)$, with the difference for the $V_{5 G y}$ the smallest (63\%).

The colour map of toxicity incidence according to small bowel dose-volume highlights that the rate of toxicity increases along both axes, i.e. there is increasing risk with increasing volume of small bowel irradiated at a given dose, and with increasing dose received by a given volume (Figure 2). This colour map can be used as a rudimentary way to derive constraints with which to inform clinical radiotherapy planning decisions. For example, if a toxicity risk of below $20 \%$ were desired, it would appear necessary to maintain $V_{5 G y}<250 \mathrm{~cm}^{3}$, $V_{10 G y}<250 \mathrm{~cm}^{3}, V_{15 G y}<100 \mathrm{~cm}^{3}, V_{20 G y}-V_{35 G y}<50 \mathrm{~cm}^{3}$. It appears that maintaining $V_{40 G y}<100 \mathrm{~cm}^{3}$ and $V_{45 G y}<50 \mathrm{~cm}^{3}$ may ensure the toxicity risk is kept below $25 \%$.

\section{Logistic regression analysis}

On logistic regression analysis of cohort toxicity risk incidence against small-bowel dose-volume, multiple small bowel cumulative dose-volume parameters were found to be significantly predictive of toxicity incidence ( $p$ value of $<0.05$ ) (Table 3 ) demonstrating a continuous relationship between increasing risk of clinicallysignificant acute toxicity with increasing volume of small-bowel irradiated to these doses. If a Bonferroni correction were used, a p-value threshold of 0.005 would apply, and only one parameter $\left(V_{10 G y}\right)$ would remain significant. Figure 3 visualises the distribution of source data points for two parameters $\left(V_{10 G y}\right.$ and $\left.V_{40 G y}\right)$ with the logistic regression model overlaid.

These models can be used to derive more accurate radiotherapy planning constraints. To maintain a projected risk of acute toxicity of $20 \%$ or less, the volume of small bowel irradiated should be kept within the following thresholds: $\mathrm{V}_{5 G \mathrm{y}}<363 \mathrm{~cm}^{3}, \mathrm{~V}_{10 G \mathrm{y}}<240 \mathrm{~cm}^{3}, \mathrm{~V}_{30 G \mathrm{y}}<92 \mathrm{~cm}^{3}, \mathrm{~V}_{35 G \mathrm{y}}<80 \mathrm{~cm}^{3}, \mathrm{~V}_{40 G \mathrm{y}}<69 \mathrm{~cm}^{3}$, and $\mathrm{V}_{45 G \mathrm{G}}<44 \mathrm{~cm}^{3}$. This should not be taken to imply that the $V_{50 G y}$ or higher have no relationship with toxicity and therefore need not be of concern, but in this analysis the data were insufficient to prove such a relationship. 


\section{Discussion}

The results of the formal meta-analysis demonstrate that, for all tested dose levels, an association exists between small bowel volume and acute toxicity in which patients who suffered toxicity had larger irradiated small bowel volumes. The absolute difference in exposure is largest for the lowest doses, and the differences become smaller with increasing dose (Figure 1). However, the relative difference in volume between the groups is actually higher as dose increases, suggesting the volume of small bowel irradiated is increasingly important as the dose increases (Table 2). When examining the average effect size across studies, the largest relative differences in small bowel volume between the cohorts of patients with or without toxicity were for the $\mathrm{V}_{30 \mathrm{~Gy}}, \mathrm{~V}_{35 \mathrm{~Gy}}$, and $\mathrm{V}_{40 \mathrm{~Gy}}$.

It is a novel finding that using population-derived small bowel data, several dose-volume parameters $\left(\mathrm{V}_{10 \mathrm{G} y}\right.$, $V_{30 G y}, V_{35 G y}$, and $V_{40 G y}$ ) were found to be predictive of toxicity incidence, in a univariate logistic regression model. For the parameter $V_{10 G y}$, the $p$-value was sufficiently low that it would remain significant if a Bonferroni correction were applied to account for multiple testing. Use of this technique has not previously been reported for the small-bowel, although similar methods have been proposed to model toxicity in the parotid gland and lung [12].

Before the age of routine $\mathrm{CT}$ imaging for radiotherapy planning, Emami et al. had limited evidence with which to define dose-volume constraints for the small bowel [21]. The advent of computerised radiotherapy planning has facilitated the analysis of 3D dose distributions, and the QUANTEC review [3] considered the results of six publications, concluding that $V_{15 G y} \geq 120 \mathrm{~cm}^{3}$ is a threshold above which the risk of acute toxicity escalates.

In this review we have shown how papers published since QUANTEC have mostly replicated earlier findings. In total, nine studies identified significant relationships between the risk of $\mathrm{Gl}$ toxicity and small bowel dosevolume parameters (from the range of $\mathrm{V}_{5 \mathrm{~Gy}}$ to $\mathrm{V}_{50 \mathrm{~Gy}}$ ), and the most repeated finding remains the $\mathrm{V}_{15 \mathrm{~Gy}}$. Further work by Robertson et al. reinforced the importance of the $V_{15 G y}$ (threshold $130 \mathrm{~cm}^{3}$ associated with a toxicity risk of $11 \%$ ) [17]. The $V_{15 G y}$ has since been highlighted in four other studies [7, 20,22, 23], including one which analysed patient reported outcomes [22].

However, the previous assumption that $15 \mathrm{~Gy}$ is a threshold volume (above which the volume irradiated is less important) is weakened by the evidence for the importance of the higher end of the DVH, such as $V_{30 G y}$ and $\mathrm{V}_{40 G \mathrm{G}}$, which were both found to be significant predictors in multiple studies. Alongside $\mathrm{V}_{15 G y}$, Arbea et al. also found that $V_{10 G y}$ (volume threshold $92.6 \mathrm{~cm}^{3}$ ) and $V_{50 G y}\left(4.4 \mathrm{~cm}^{3}\right)$ [23] predicted risk of diarrhoea, while Reis et al. found $V_{5 G y}\left(291.9 \mathrm{~cm}^{3}\right)$ [7]. Banerjee et al. found that among their patients, all of $V_{15 G y}-V_{45 G y}$ were associated with a risk of small bowel toxicity [20]. Several publications have reported evidence of a volume effect for the small bowel exposed to $50 \mathrm{~Gy}$. As dose escalation becomes more popular in the treatment of rectal cancer, with the intent of improving response rates [24], the importance of higher dose thresholds [23] may become even more apparent.

In the available literature the volume effect has not been tested at doses below $5 \mathrm{~Gy}$, however the data have not suggested that there is a threshold below which exposure has no implications for risk of toxicity, a point which could in theory negate the intended benefit of techniques such as IMRT which can increase the volume 
irradiated to low dose. However, as reduced toxicity has been demonstrated when pelvic IMRT is implemented, it may be that the benefit of reduced high dose exposure outweighs the cost [25].

\section{Study Limitations}

As data from randomised controlled trials were not available, this meta-analysis has used data from retrospective, observational non-randomised studies, which brings greater risk of bias and confounds. Importantly, all the studies used data from a single centre, sometimes by a single clinician. Unfortunately, not only were there few studies providing suitable data for inclusion in this work, the availability of study data also appears to have been affected by publication bias: there is reason to suspect that studies failing to show significant associations between DVH and toxicity were less likely to be published. The sparsity of source data has led us to adopt solutions such as plot digitisation and data interpolation, and we acknowledge that these may lack precision, particularly when the spline-fitting method has been used to recreate the DVH from few reported data points. The studies themselves are at risk of bias affecting their results, and this analysis has shown heterogeneity of size of treatment effect between the studies.

There is heterogeneity in the methods used to collect toxicity outcomes data and in the treatment that was delivered. Only DVH data regarding small bowel outlined as 'individual loops' has been analysed, but some variation persists, for example, some groups only contoured loops of bowel that contained oral contrast. While different methods and tools have been used for the collation and grading of toxicity symptoms, there are major key similarities between these, and it has been possible to translate grades between different scales. There was some inconsistency in the definition of the relevant toxicity endpoint, where many studies used terminology such as 'lower GI toxicity' or 'small bowel toxicity', but without usually specifying the toxicity events or symptoms that constitute such a description. Others reported only the rate of any nonhaematological toxicity, or conversely only the incidence of a single specific symptom ('diarrhoea' or 'watery stool' were both used). All studies except for one (Chen et al. [22]) relied on clinician-assessed toxicity, whereas potential benefits that may come from the use of patient-reported outcomes include greater breadth and sensitivity for the symptoms that trouble patients after their treatment for cancer [26]. Furthermore, the use of supportive medications such as anti-emetics and anti-diarrhoeal drugs, in a prophylactic or reactive context, was not comprehensively reported, and as such the possible interaction with the effect of dosevolume cannot be ascertained.

All the studies providing data for this analysis collected information regarding only acute toxicity. No studies could be identified in our literature search that had collected small-bowel DVH data in relation to late toxicity after radiotherapy for rectal cancer. Two studies with data from treatment of cervix cancer were found [27, 28] and one from treatment of pancreatic cancer [29]. Late toxicity tends to develop gradually through a complex ongoing inflammatory process influenced by many host and treatment factors, and it is likely to be more difficult to establish a relationship with radiotherapy DVH parameters.

To benefit future work in this field would require consistent application of consensus guidelines on data acquisition, widespread prospective collection of detailed objective toxicity outcomes, wider publication of important negative findings, and increased data sharing between institutions, which can be facilitated by open-source, manufacturer-independent tools such as the Computational Environment for Radiotherapy Research (CERR) [30]. The increasing use of radiotherapy dose escalation may provide an opportunity to study the small bowel dose-volume effect at doses greater than $50 \mathrm{~Gy}$, and the effect of very-low dose should also be examined, in which the use of patient-reported outcome measures may possibly improve sensitivity to 
lower-grade toxicity. There remains a paucity of collaborative analysis of large prospective clinical trial cohorts, and efforts to achieve this should be supported and congratulated.

In conclusion, review and analysis of published clinical cohort dose-volume data with toxicity outcomes has demonstrated the significant dose-volume-toxicity response effect for a wide range of clinically-relevant doses in the treatment of rectal cancer to refine the understanding of the parameters important in this relationship and their relationship with outcomes. We have shown how toxicity is not only associated with largest absolute differences in the volume of small bowel irradiated to low dose $\left(V_{5 G y}\right)$, but also with largest relative differences in volume irradiated to higher doses $\left(\mathrm{V}_{35 \mathrm{G}}-\mathrm{V}_{40 \mathrm{~Gy}}\right)$. Furthermore, cohort-derived small bowel dose-volume parameters $\left(V_{10 G y}, V_{30 G y}, V_{35 G y}\right.$ and $\left.V_{40 G y}\right)$ were found to be significantly predictive of the toxicity incidence in that population in a univariate logistic regression model. These models have been used to derive radiotherapy planning constraints below which the risk of toxicity should be less than $20 \%$ : $V_{5 G y}<363 \mathrm{~cm}^{3}, V_{10 G y}<240 \mathrm{~cm}^{3}$, $V_{30 G y}<92 \mathrm{~cm}^{3}, V_{35 G y}<80 \mathrm{~cm}^{3}, V_{40 G y}<69 \mathrm{~cm}^{3}$, and $V_{45 G y}<44 \mathrm{~cm}^{3}$. However, a key point is that the relationship between irradiated volume and risk of toxicity is continuous, without a threshold below which the risk is unaltered, hence the priority of clinicians and planners should be to minimise exposure of normal tissue, regardless of such constraints. 


\section{References}

[1] Gérard J-P, Azria D, Gourgou-Bourgade S, et al. Clinical outcome of the ACCORD 12/0405 PRODIGE 2 randomized trial in rectal cancer. Journal of Clinical Oncology. 2012;30:4558-65.

[2] Bosset JF, Calais G, Daban A, et al. Preoperative chemoradiotherapy versus preoperative radiotherapy in rectal cancer patients: assessment of acute toxicity and treatment compliance: Report of the 22921 randomised trial conducted by the EORTC Radiotherapy Group. European Journal of Cancer. 2004;40:219-24.

[3] Kavanagh BD, Pan CC, Dawson LA, et al. Radiation dose-volume effects in the stomach and small bowel. Int J Radiat Oncol Biol Phys. 2010;76:S101-7.

[4] Burbach JPM, den Harder AM, Intven M, van Vulpen M, Verkooijen HM, Reerink O. Impact of radiotherapy boost on pathological complete response in patients with locally advanced rectal cancer: A systematic review and meta-analysis. Radiother Oncol. 2014;113:1-9.

[5] Moher D, Liberati A, Tetzlaff J, et al. Preferred reporting items for systematic reviews and meta-analyses: The PRISMA statement. PLoS medicine. 2009;6.

[6] Gunnlaugsson A, Kjellen E, Nilsson P, Bendahl PO, Willner J, Johnsson A. Dose-volume relationships between enteritis and irradiated bowel volumes during 5 -fluorouracil and oxaliplatin based chemoradiotherapy in locally advanced rectal cancer. Acta Oncol. 2007;46:937-44.

[7] Reis T, Khazzaka E, Welzel G, Wenz F, Hofheinz RD, Mai S. Acute small-bowel toxicity during neoadjuvant combined radiochemotherapy in locally advanced rectal cancer: determination of optimal dose-volume cutoff value predicting grade 2-3 diarrhoea. Radiat Oncol. 2015;10:30.

[8] The Cochrane Collaboration. Review Manager (RevMan). 5.3 ed. Copenhagen: The Nordic Cochrane Centre; 2014.

[9] The Cochrane Collaboration. Cochrane Handbook for Systematic Reviews of Interventions. In: JPT H, S G, editors.: The Cochrane Collaboration; 2011.

[10] Sterne JAC, Sutton AJ, loannidis JPA, et al. Recommendations for examining and interpreting funnel plot asymmetry in meta-analyses of randomised controlled trials. BMJ. 2011;343.

[11] Jackson A, Yorke ED, Rosenzweig KE. The atlas of complication incidence: a proposal for a new standard for reporting the results of radiotherapy protocols. Seminars in radiation oncology. 2006;16:260-8.

[12] Semenenko VA, Li XA. Lyman-Kutcher-Burman NTCP model parameters for radiation pneumonitis and xerostomia based on combined analysis of published clinical data. Phys Med Biol. 2008;53:737-55.

[13] Marks LB, Bentzen SM, Deasy JO, et al. Radiation dose-volume effects in the lung. Int J Radiat Oncol Biol Phys. 2010;76:S70-6.

[14] Xu B, Guo Y, Chen Y, et al. Is the irradiated small bowel volume still a predictor for acute lower gastrointestinal toxicity during preoperative concurrent chemo-radiotherapy for rectal cancer when using intensity-modulated radiation therapy? Radiat Oncol. 2015;10.

[15] Baglan KL, Frazier RC, Yan D, Huang RR, Martinez AA, Robertson JM. The dose-volume relationship of acute small bowel toxicity from concurrent 5-FU-based chemotherapy and radiation therapy for rectal cancer. International Journal of Radiation Oncology Biology Physics. 2002;52:176-83.

[16] Tho LM, Glegg M, Paterson J, et al. Acute small bowel toxicity and preoperative chemoradiotherapy for rectal cancer: investigating dose-volume relationships and role for inverse planning. International Journal of Radiation Oncology Biology Physics. 2006;66:505-13.

[17] Robertson JM, Söhn M, Yan D. Predicting Grade 3 Acute Diarrhea During Radiation Therapy for Rectal Cancer Using a Cutoff-Dose Logistic Regression Normal Tissue Complication Probability Model. International Journal of Radiation Oncology Biology Physics. 2010;77:66-72. 
[18] Baglan KL, Frazier RC, Yan D, Huang RR, Martinez AA, Robertson JM. The dose-volume realationship of acute small bowel toxicity from concurrent 5-FU-based chemotherapy and radiation therapy for rectal cancer. International Journal of Radiation Oncology Biology Physics. 2002;52:176-83.

[19] Robertson JM, Lockman D, Yan D, Wallace M. The Dose-Volume Relationship of Small Bowel Irradiation and Acute Grade 3 Diarrhea During Chemoradiotherapy for Rectal Cancer. International Journal of Radiation Oncology Biology Physics. 2008;70:413-8.

[20] Banerjee R, Chakraborty S, Nygren I, Sinha R. Small bowel dose parameters predicting grade $>3$ acute toxicity in rectal cancer patients treated with neoadjuvant chemoradiation: an independent validation study comparing peritoneal space versus small bowel loop contouring techniques. Int J Radiat Oncol Biol Phys. 2013;85:1225-31.

[21] Emami B, Lyman J, Brown A, et al. Tolerance of normal tissue to therapeutic irradiation. Int J Radiat Oncol Biol Phys. 1991;21:109-22.

[22] Chen RC, Mamon HJ, Ancukiewicz M, et al. Dose-volume effects on patient-reported acute gastrointestinal symptoms during chemoradiation therapy for rectal cancer. International Journal of Radiation Oncology Biology Physics. 2012;83:e513-e7.

[23] Arbea L, Ramos L, Beunza J, et al. Dosimetric predictors of gastrointestinal toxicity during intensity modulated radiation therapy concomitant with capecitabine and oxaliplatin for locally advanced rectal cancer. International Journal of Radiation Oncology Biology Physics. 2012;1):S795.

[24] Teoh S, Muirhead R. Rectal Radiotherapy - Intensity-modulated Radiotherapy Delivery, Delineation and Doses. Clin Oncol (R Coll Radiol). 2016;28:93-102.

[25] Samuelian JM, Callister MD, Ashman JB, Young-Fadok TM, Borad MJ, Gunderson LL. Reduced acute bowel toxicity in patients treated with intensity-modulated radiotherapy for rectal cancer. Int J Radiat Oncol Biol Phys. 2012;82:1981-7.

[26] Gilbert A, Ziegler L, Martland M, et al. Systematic Review of Radiation Therapy Toxicity Reporting in Randomized Controlled Trials of Rectal Cancer: A Comparison of Patient-Reported Outcomes and Clinician Toxicity Reporting. Int J Radiat Oncol Biol Phys. 2015;92:555-67.

[27] Chen MF, Tseng CJ, Tseng CC, Kuo YC, Yu CY, Chen WC. Clinical outcome in posthysterectomy cervical cancer patients treated with concurrent cisplatin and intensity-modulated pelvic radiotherapy: comparison with conventional radiotherapy. International Journal of Radiation Oncology Biology Physics. 2007;67:143844.

[28] Chopra S, Dora T, Chinnachamy AN, et al. Predictors of grade 3 or higher late bowel toxicity in patients undergoing pelvic radiation for cervical cancer: results from a prospective study. Int J Radiat Oncol Biol Phys. 2014;88:630-5.

[29] Abelson JA, Murphy JD, Minn AY, et al. Intensity-modulated radiotherapy for pancreatic adenocarcinoma. International Journal of Radiation Oncology Biology Physics. 2012;82:e595-e601.

[30] Deasy JO, Blanco Al, Clark VH. CERR: a computational environment for radiotherapy research. Medical physics. 2003;30:979-85.

[31] Van Der Voort Van Zyp JRN, Ceha H, Niehe V, Putter H, Marinelli A, Marijnen C. Acute toxicity after a diverting stoma and spacer prior to chemoradiation in locally advanced rectal cancer. Radiother Oncol. 2012;103:S420. 


\section{Tables}

\begin{tabular}{|c|c|c|c|c|c|c|c|c|c|}
\hline Reference & Data & $N=$ & $\begin{array}{l}\text { Concurrent } \\
\text { chemo }\end{array}$ & RT dose [Gy] & RT planning & Toxicity outcome & $\begin{array}{l}\text { Toxicity } \\
\text { scale }\end{array}$ & $\begin{array}{c}\text { Toxicity } \\
\text { incidence }\end{array}$ & $\begin{array}{l}\text { Small bowel dose-volume parameter predictive of toxicity } \\
\text { (with threshold if reported) }\end{array}$ \\
\hline $\begin{array}{c}\text { Baglan } \\
2002[15]\end{array}$ & $\mathrm{R}$ & 40 & 5-FU & $\begin{array}{l}50.4 \mathrm{~Gy} \text { in } 28 \# \\
\text { (45 Gy to pelvis) }\end{array}$ & 3D-CRT & $\begin{array}{l}\text { Acute small bowel } \\
\quad \text { Grade } \geq 3\end{array}$ & CTC v2 & $25 \%$ & $\mathrm{~V}_{15 \mathrm{~Gy}} 150 \mathrm{~cm}^{3}$ \\
\hline $\begin{array}{c}\text { Tho } \\
2006[16]\end{array}$ & $P$ & 41 & 5-FU & 45 Gy in $25 \#$ & 3D-CRT & $\begin{array}{l}\text { Acute diarrhoea } \\
\text { Grade } \geq 2\end{array}$ & $\begin{array}{c}\text { CTCAE } \\
\text { v3 }\end{array}$ & $20 \%$ & $V_{5 G y}$ to $V_{42.75 G y}$ \\
\hline $\begin{array}{l}\text { Gunnlaugsson } \\
2007[6]\end{array}$ & $\mathrm{R}$ & 28 & $\begin{array}{l}\text { Oxaliplatin \& } \\
\text { 5-FU }\end{array}$ & $\begin{array}{l}50.4 \text { Gy in } 28 \#(n=15) \\
50 \text { Gy in } 25 \#(n=13)\end{array}$ & 3D-CRT & $\begin{array}{l}\text { Acute diarrhoea } \\
\text { Grade } \geq 2\end{array}$ & CTC v2 & $29 \%$ & $V_{15 G y}$ to $V_{45 G y}$ \\
\hline $\begin{array}{c}\text { Robertson } \\
2008[19]\end{array}$ & $\mathrm{P}$ & 96 & 5-FU & 45 Gy in $25 \#$ & 3D-CRT & $\begin{array}{l}\text { Acute diarrhoea } \\
\text { Grade } \geq 3\end{array}$ & $\begin{array}{c}\text { CTCAE } \\
\text { v3 }\end{array}$ & $21 \%$ & $\begin{array}{l}V_{56 y} 500 \mathrm{~cm}^{3}, V_{10 G y} 300 \mathrm{~cm}^{3}, V_{15 G y} 150 \mathrm{~cm}^{3}, V_{20 G y} 145 \mathrm{~cm}^{3} \\
V_{25 G y} 140 \mathrm{~cm}^{3}, V_{30 G y} 135 \mathrm{~cm}^{3}, V_{35 G y} 130 \mathrm{~cm}^{3}, V_{40 G y} 125 \mathrm{~cm}^{3}\end{array}$ \\
\hline $\begin{array}{c}\text { Robertson } \\
2010[17]\end{array}$ & Mix & 152 & 5-FU & 45 Gy in $25 \#$ & 3D-CRT & $\begin{array}{l}\text { Acute diarrhoea } \\
\text { Grade } \geq 3\end{array}$ & $\begin{array}{c}\text { CTCAE } \\
\text { v3 }\end{array}$ & $21 \%$ & $\mathrm{~V}_{15 \mathrm{~Gy}} 130 \mathrm{~cm}^{3}$ \\
\hline $\begin{array}{c}\text { Arbea } \\
2012[23]\end{array}$ & $\mathrm{R}$ & 100 & $\begin{array}{l}\text { Capecitabine- } \\
\text { oxaliplatin }\end{array}$ & $47.5 \mathrm{~Gy}$ in $20 \#$ & IMRT & $\begin{array}{l}\text { Acute diarrhoea } \\
\text { Grade } \geq 3\end{array}$ & NS & $9 \%$ & $\mathrm{~V}_{10 G \mathrm{y}} 92.6 \mathrm{~cm}^{3}, \mathrm{~V}_{15 G \mathrm{y}} 78.8 \mathrm{~cm}^{3}, \mathrm{~V}_{50 \mathrm{~Gy}} 4.44 \mathrm{~cm}^{3}$ \\
\hline $\begin{array}{c}\text { Chen } \\
2012[22]\end{array}$ & $P$ & 66 & $\begin{array}{c}5-\mathrm{FU} / \\
\text { capecitabine }\end{array}$ & $50.4 \mathrm{~Gy}$ in $28 \#$ & 3D-CRT & Patient-reported GI & PROM & $13 \%$ & $V_{15 G y}$ \\
\hline $\begin{array}{l}\text { Van der Voort van Zyp } \\
2012[31]\end{array}$ & $\mathrm{R}$ & 189 & NS & NS & NS & $\begin{array}{l}\text { Acute small bowel } \\
\text { Grade } \geq 3\end{array}$ & $\begin{array}{l}\text { CTCAE } \\
\text { v4 }\end{array}$ & $16 \%$ & \\
\hline $\begin{array}{l}\text { Banerjee } \\
2013[20]\end{array}$ & R & 67 & 5-FU & $50.4 \mathrm{~Gy}$ in $28 \#$ & 3D-CRT & $\begin{array}{l}\text { Acute small bowel } \\
\text { Grade } \geq 3\end{array}$ & RTOG & $16 \%$ & $\begin{array}{c}V_{15 G y}-V_{45 G y} ; V_{25 G y} 190 \mathrm{~cm}^{3}\left(650 \mathrm{~cm}^{3} \text { for peritoneal cavity) }\right. \\
V_{15 G y} 275 \mathrm{~cm}^{3}\left(830 \mathrm{~cm}^{3} \text { for peritoneal cavity) }\right.\end{array}$ \\
\hline $\begin{array}{c}\text { Reis } \\
2015[7]\end{array}$ & $P$ & 45 & $\begin{array}{l}\text { Cetuximab, cape, } \\
\text { irinotecan }\end{array}$ & 50.4 Gy in $28 \#$ & 3D-CRT & Acute diarrhoea & $\begin{array}{c}\text { CTCAE } \\
\text { v3 }\end{array}$ & $29 \%$ & $\begin{array}{l}V_{5 G y}>291.94 \mathrm{~cm}^{3} \\
V_{15 G y}>125.5 \mathrm{~cm}^{3}\end{array}$ \\
\hline $\begin{array}{c}\mathrm{Xu} \\
2015[14]\end{array}$ & $\mathrm{R}$ & 63 & $\begin{array}{l}\text { Oxaliplatin \& } \\
\text { capecitabine }\end{array}$ & 50 Gy in $25 \#$ & IMRT & $\begin{array}{l}\text { Acute lower-GI } \\
\text { Grade } \geq 2\end{array}$ & $\begin{array}{l}\text { CTCAE } \\
\text { v3 }\end{array}$ & $35 \%$ & No parameters found to be predictive \\
\hline
\end{tabular}

Table 1. Summary details of papers reporting dose-volume and toxicity data for small bowel and/or analyses of the dose-volume relationship for the small bowel in the treatment of rectal cancer with radiotherapy. Papers providing DVH data are highlighted in bold. Findings from DVH-toxicity analyses are summarised in the final column.

$(\mathrm{R}=$ retrospective, $\mathrm{P}=$ prospective $\mathrm{NS}=$ not specified; IMRT= intensity modulated radiotherapy; $\mathrm{Gl}=$ gastrointestinal, 5 -FU = 5-fluorouracil, cape = capecitabine, $\mathrm{CTCAE}=$ Common Terminology Criteria for Adverse Events, RTOG = Radiation Therapy Oncology Group Acute Radiation Morbidity Scoring Criteria, PROM = Patient-Reported Outcome Measures) 


\begin{tabular}{|c|c|c|c|c|c|}
\hline & \multirow{2}{*}{\multicolumn{2}{|c|}{$\begin{array}{c}\text { Primary analysis } \\
\text { All studies (Baglan, Banerjee \& Robertson) }\end{array}$}} & \multicolumn{3}{|c|}{ Leave-one out analysis } \\
\hline & & & Round 1 & Round 2 & Round 3 \\
\hline \multirow{3}{*}{$\begin{array}{l}\text { Participants } \\
\text { analysed }\end{array}$} & 203 & & 163 & 136 & 107 \\
\hline & Mean absolute difference $\left[\mathrm{cm}^{3}\right]$ & Relative & \multirow{2}{*}{\multicolumn{3}{|c|}{ Absolute difference $\left[\mathrm{cm}^{3}\right]$ ( $95 \%$ confidence interval) }} \\
\hline & (95\% confidence interval) & difference & & & \\
\hline $\mathrm{V}_{5 \mathrm{~Gy}}$ & $299(225-373)$ & $81 \%$ & $285(204-367)$ & $236(133-339)$ & $364(274-454)$ \\
\hline$V_{10 G y}$ & $275(206-343)$ & $131 \%$ & $274(197-351)$ & $197(102-293)$ & $332(250-413)$ \\
\hline$V_{15 G y}$ & $212(164-261)$ & $170 \%$ & $230(164-297)$ & $166(110-223)$ & $245(189-301)$ \\
\hline$V_{20 G y}$ & $198(152-243)$ & $189 \%$ & $216(153-280)$ & $152(100-205)$ & $232(178-285)$ \\
\hline$V_{25 G y}$ & $184(142-227)$ & $219 \%$ & $198(141-254)$ & $141(91-191)$ & $217(167-266)$ \\
\hline$V_{30 G y}$ & $148(109-186)$ & $219 \%$ & $141(91-190)$ & $121(74-168)$ & $180(134-226)$ \\
\hline$V_{35 G y}$ & $138(100-175)$ & $227 \%$ & $130(82-177)$ & 114 (69-159) & $169(124-214)$ \\
\hline$V_{40 G y}$ & $128(92-164)$ & $240 \%$ & $122(76-167)$ & $104(60-148)$ & $157(114-200)$ \\
\hline
\end{tabular}

Table 2. Results of meta-analysis including absolute and relative differences in volume of small bowel irradiated to threshold dose VxGy, between patients with Grade 0-2 and those with Grade $\geq 3$ toxicity. Source data was compiled from Baglan 2002, Banerjee 2013 and Robertson 2008 (total $n=203$ ). 
(a) Absolute differences $\left[\mathrm{cm}^{3}\right]$ in small bowel volume between patients with or without toxicity

\begin{tabular}{|c|c|c|c|c|c|c|c|c|c|c|c|}
\hline & $\mathrm{n}$ & $V_{5 G y}$ & $\mathrm{~V}_{10 \mathrm{~Gy}}$ & $V_{15 G y}$ & $V_{20 G y}$ & $V_{25 G y}$ & $V_{30 G y}$ & $V_{35 G y}$ & $\mathrm{~V}_{40 \mathrm{~Gy}}$ & $\mathrm{~V}_{45 \mathrm{~Gy}}$ & $V_{50 G y}$ \\
\hline Tho 2006 & 41 & 252 & 228 & 190 & 94 & 70 & 64 & 54 & 23 & & \\
\hline Gunnlaugsson 07 & 28 & 155 & 165 & 195 & 210 & 199 & 176 & 164 & 157 & 140 & 88 \\
\hline Reis 2015 & 45 & 182 & 157 & 103 & 46 & 36 & 27 & 26 & 22 & 3 & \\
\hline Xu 2015 & 63 & -51 & -41 & -34 & -31 & -24 & -15 & -10 & -7 & & \\
\hline Baglan 2002 & 40 & 359 & 278 & 192 & 178 & 168 & 159 & 151 & 138 & & \\
\hline Banerjee 2013 & 67 & 366 & 356 & 338 & 338 & 293 & 205 & 191 & 178 & 44 & \\
\hline Robertson 2008 & 96 & 167 & 139 & 121 & 107 & 96 & 74 & 67 & 62 & & \\
\hline Weighted mean & 380 & 196 & 176 & 152 & 131 & 116 & 92 & 86 & 77 & & \\
\hline
\end{tabular}

(b) Relative differences in small bowel volume between patients with or without toxicity

\begin{tabular}{|c|c|c|c|c|c|c|c|c|c|c|c|}
\hline & n & $V_{5 G y}$ & $V_{10 G y}$ & $V_{15 G y}$ & $V_{20 G y}$ & $V_{25 G y}$ & $V_{30 G y}$ & $V_{35 G y}$ & $\mathrm{~V}_{40 \mathrm{~Gy}}$ & $\mathrm{~V}_{45 \mathrm{~Gy}}$ & $V_{50 G y}$ \\
\hline Gunnlaugsson 07 & 28 & $69 \%$ & $81 \%$ & $129 \%$ & $269 \%$ & $307 \%$ & $300 \%$ & $289 \%$ & $302 \%$ & $292 \%$ & $263 \%$ \\
\hline Reis 2015 & 45 & $68 \%$ & $79 \%$ & $110 \%$ & $72 \%$ & $69 \%$ & $59 \%$ & $77 \%$ & $81 \%$ & $25 \%$ & \\
\hline Xu 2015 & 63 & $-19 \%$ & $-18 \%$ & $-17 \%$ & $-18 \%$ & $-19 \%$ & $-20 \%$ & $-21 \%$ & $-23 \%$ & & \\
\hline Baglan 2002 & 40 & $82 \%$ & $113 \%$ & $151 \%$ & $165 \%$ & $170 \%$ & $173 \%$ & $176 \%$ & $177 \%$ & & \\
\hline Banerjee 2013 & 67 & $160 \%$ & $193 \%$ & $218 \%$ & $256 \%$ & $326 \%$ & $366 \%$ & $406 \%$ & $456 \%$ & $191 \%$ & \\
\hline Robertson 2008 & 96 & $37 \%$ & $65 \%$ & $119 \%$ & $129 \%$ & $130 \%$ & $112 \%$ & $110 \%$ & $115 \%$ & & \\
\hline Weighted mean & 339 & $63 \%$ & $84 \%$ & $117 \%$ & $135 \%$ & $152 \%$ & $153 \%$ & $162 \%$ & $175 \%$ & & \\
\hline
\end{tabular}

(c) Logistic regression parameters

\begin{tabular}{ccccccccccc}
\hline Parameter & $\mathbf{V}_{\text {5Gy }}$ & $\mathbf{V}_{\text {10Gy }}$ & $\mathbf{V}_{\text {15Gy }}$ & $\mathbf{V}_{\text {20Gy }}$ & $\mathbf{V}_{\text {25Gy }}$ & $\mathbf{V}_{\text {30Gy }}$ & $\mathbf{V}_{\text {35Gy }}$ & $\mathbf{V}_{\text {40Gy }}$ & $\mathbf{V}_{\text {45Gy }}$ & $\mathbf{V}_{\text {50Gy }}$ \\
\hline B for VxGy & 0.002 & 0.005 & 0.004 & 0.003 & 0.005 & 0.007 & 0.008 & 0.008 & 0.009 & 0.010 \\
\hline SE for B & 0.001 & 0.002 & 0.002 & 0.002 & 0.003 & 0.003 & 0.004 & 0.004 & 0.004 & 0.006 \\
\hline Intercept & -2.11 & -2.63 & -2.05 & -1.8 & -1.92 & -2.01 & -1.99 & -1.93 & -1.79 & -1.54 \\
\hline SE for intercept & 0.29 & 0.43 & 0.36 & 0.29 & 0.29 & 0.29 & 0.26 & 0.23 & 0.18 & 0.12 \\
\hline$P$ value for $V_{\text {xGy }}$ & $\mathbf{0 . 0 1 7}$ & $\mathbf{0 . 0 0 4}$ & 0.095 & 0.227 & 0.108 & $\mathbf{0 . 0 4 6}$ & $\mathbf{0 . 0 3 4}$ & $\mathbf{0 . 0 2 6}$ & $\mathbf{0 . 0 3 3}$ & 0.143 \\
\hline & & & & & & & & & & \\
\hline 20\% risk constraint $\left[\mathrm{cm}^{3}\right]$ & $\mathbf{3 6 3}$ & $\mathbf{2 4 0}$ & & & & $\mathbf{9 2}$ & $\mathbf{8 0}$ & $\mathbf{6 9}$ & $\mathbf{4 4}$ &
\end{tabular}

Table 3. Differences in cumulative (a) absolute and (b) relative volume of small bowel irradiated at each dose level between patients with or without toxicity as defined in each study. Relative change for data from Tho et al. could not be included as the irradiated volume for the patients without toxicity was zero. (c) Logistic regression model coefficients with standard error (SE) for each small bowel DVH parameter, with statistical significance of logistic regression model fit to risk of Grade $\geq$ 3 toxicity. $P$ values $<0.05$ indicated in bold. P values $<0.005$ indicated by italic typeface. $20 \%$ risk constraint denotes an irradiated volume associated with a $20 \%$ risk of acute toxicity. 


\section{Figures and captions}

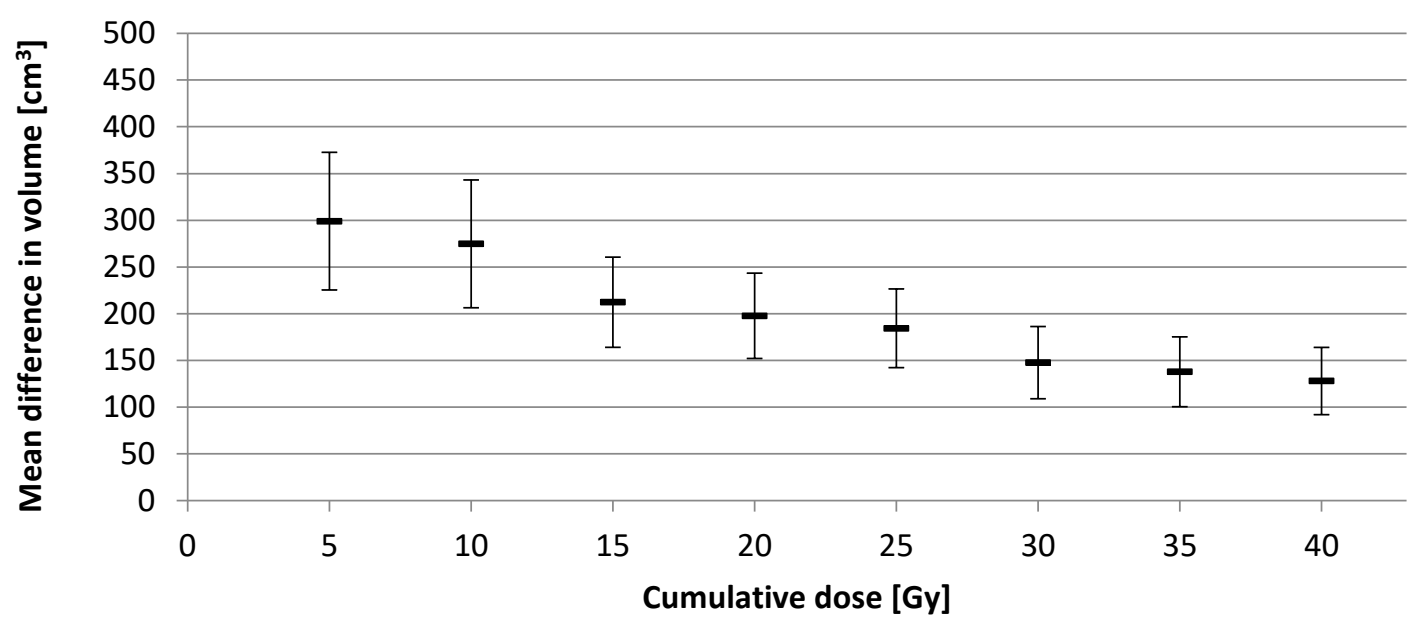

Figure 1. Results of inverse-variance fixed-effect meta-analysis for data compiled from Baglan 2002, Banerjee 2013 and Robertson 2008 (total $n=203$ ). Figure shows mean difference in volume of small bowel irradiated to specified dose levels between patients with Grade 0-2 and those with Grade $\geq 3$ toxicity (error bars indicate 95\% confidence intervals). 


\begin{tabular}{|c|c|c|c|c|c|c|c|c|c|c|}
\hline 500 & $10 / 40$ & & & & & & & & & \\
\hline 450 & $20 / 96$ & & & & & & & & & \\
\hline 400 & & & & & & & & & & \\
\hline 350 & $13 / 45$ & & & & & & & & & \\
\hline 300 & & $10 / 40$ & & & & & & & & \\
\hline 250 & $19 / 95$ & $21 / 73$ & & & & & & & & \\
\hline 200 & $9 / 66$ & $31 / 163$ & $19 / 95$ & & & & & & & \\
\hline 150 & & $30 / 189$ & $53 / 274$ & $29 / 135$ & & & & & & \\
\hline 100 & & & $20 / 96$ & $20 / 96$ & $29 / 135$ & $18 / 68$ & $18 / 68$ & $18 / 68$ & $8 / 28$ & \\
\hline 50 & $4 / 41$ & $4 / 41$ & $9 / 66$ & $13 / 45$ & $33 / 141$ & $44 / 208$ & $44 / 208$ & $44 / 208$ & & $8 / 28$ \\
\hline 0 & & & $4 / 41$ & $4 / 41$ & $13 / 107$ & $4 / 41$ & $13 / 107$ & $17 / 86$ & $24 / 112$ & \\
\hline & $V_{5 G y}$ & $\mathrm{~V}_{10 \mathrm{~Gy}}$ & $V_{15 G y}$ & $V_{20 G y}$ & $\mathrm{~V}_{25 \mathrm{~Gy}}$ & $V_{30 G y}$ & $\mathrm{~V}_{35 \mathrm{~Gy}}$ & $\mathrm{~V}_{40 \mathrm{~Gy}}$ & $\mathrm{~V}_{45 \mathrm{~Gy}}$ & $V_{50 G y}$ \\
\hline
\end{tabular}

\begin{tabular}{|l|l|l|l|l|l|l|l|l|l|} 
Colour key (toxicity risk) & $10.0 \%$ & $12.5 \%$ & $15.0 \%$ & $17.5 \%$ & $20.0 \%$ & $22.5 \%$ & $25.0 \%$ & $27.5 \%$ & $30.0 \%$ \\
\hline
\end{tabular}

Figure 2. Colour maps of toxicity risk associated with irradiation of small bowel to indicated dose-volumes.

Values in cells indicate observed toxicity incidence for studies or cohorts whose DVH intersects in the relevant dose-volume range. Cells are colour-labelled according to risk, as per the key. Cells not containing numerical values had no data available, but for the purpose of the figure the colour has been interpolated in gaps between cells with data. 
(a)

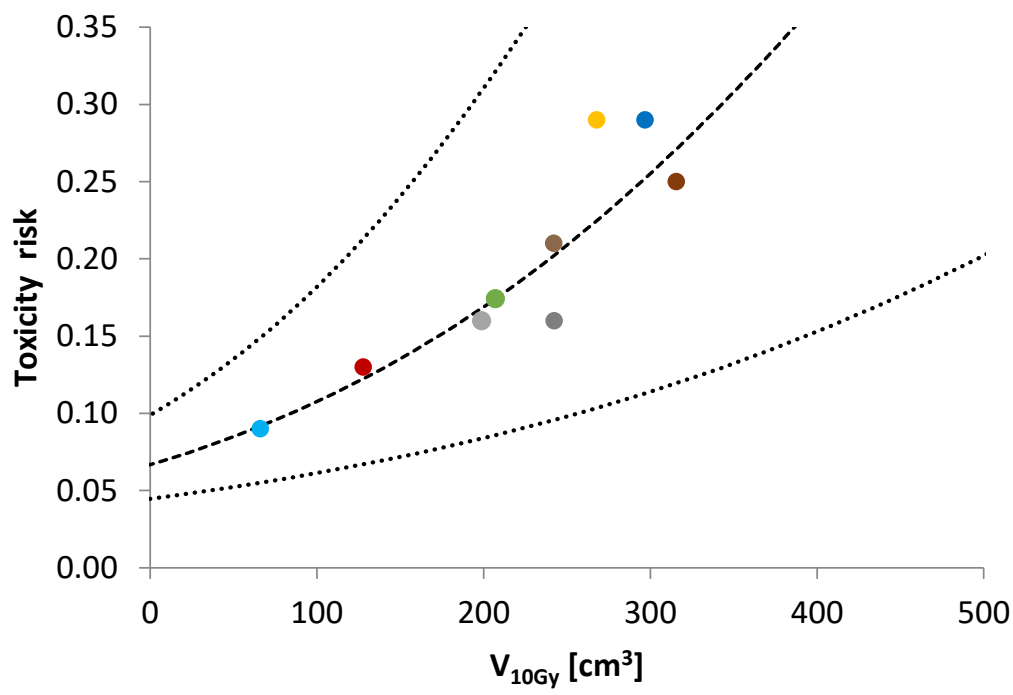

- Baglan (10/40)

- Banerjee (11/67)

- Chen 2012 (9/66)

- Gunnlaugsson (8/28)

- Reis (13/45)

- Robertson (20/96)

- Tho (4/41)

- Van der Voort (30/189)

- Xu $(22 / 63)$

------- Logistic model

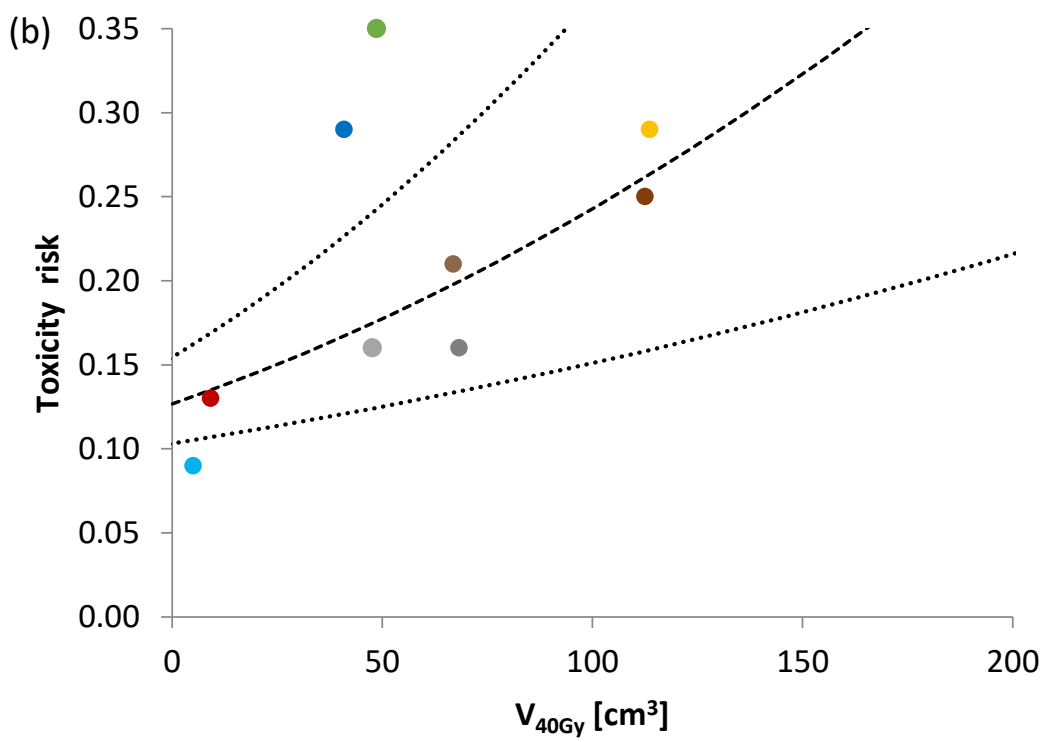

Figure 3. Plot of reported toxicity rate against small bowel (a) $V_{10 G y}\left[\mathrm{~cm}^{3}\right]$ and (b) v40Gy with univariate logistic regression model (dashed line) and 69\% confidence interval for model parameters (dotted lines). 